\title{
Nuclear Fuel Cycle Analysis Technology to Develop Advanced Nuclear Fuel Cycle
}

\section{선진 핵 연료주기 기술 개발을 위한 핵연료주기 분석 기술}

\author{
Byung Heung Park' ${ }^{1)}$ and Won Il Ko* \\ Chungju National University, 50 Daehak-ro, Chungju-si, Chungbuk, Korea \\ *Korea Atomic Energy Research Institute, 1045 Daedeok-daero, Yuseong-gu, Daejeon, Korea \\ 박병흥1), 고원일* \\ 충주대학교, 충청북도 충주시 대학로 50 \\ *한국원자력연구원, 대전광역시 유성구 대덕대로 1045
}

(Received October 25, 2011 / Revised November 14, 2011 / Approved November 15, 2011)

\begin{abstract}
The nuclear fuel cycle (NFC) analysis is a study to set a NFC policy and to promote systematic researches by analyzing technologies and deriving requirements at each stage of a fuel cycle. System analysis techniques are utilized for comparative analysis and assessment of options on a considered system. In case that NFC is taken into consideration various methods of the system analysis techniques could be applied depending on the range of an interest. This study presented NFC analysis strategies for the development of a domestic advanced NFC and analysis techniques applicable to different phases of the analysis.

Strategically, NFC analysis necessitates the linkage with technology analyses, domestic and international interests, and a national energy program. In this respect, a trade-off study is readily applicable since it includes various aspects on NFC as metrics and then analyzes the considered NFC options according to the derived metrics. In this study, the trade-off study was identified as a method for NFC analysis with the derived strategies and it was expected to be used for development of an advanced NFC. A technology readiness level (TRL) method and NFC simulation codes could be utilized to obtain the required metrics and data for assessment in the trade-off study. The methodologies would guide a direction of technology development by comparing and assessing technological, economical, environmental, and other aspects on the alternatives. Consequently, they would contribute for systematic development and deployment of an appropriate advanced NFC.
\end{abstract}

Key words : Nuclear Fuel Cycle Analysis, Advanced Nuclear Fuel Cycle, Trade-off Study, Technology Readiness Level, Nuclear Fuel Cycle Simulator

요 약

핵연료주기 분석 연구는 핵연료주기 단계에서 기술들을 분석하고 요건들을 도출하여 국가적 핵연료주기 정책 설정 및 추진을 체계적으로 수행하기 위한 연구이다. 시스템 분석 기술은 대상 시스템의 비교 분석 평가 에 활용되며 핵연료주기를 대상으로 하는 경우 각 국가 또는 관심 범위에 따라 다양한 방법이 사용된다. 본

1) Corresponding Author. E-mail : b.h.park@cjnu.ac.kr 
연구에서는 국내 선진 핵연료주기 개발을 위해 필요한 핵연료주기 분석 전략과 함께 이를 위해 사용될 수 있 는 분석 기술들을 제시하였다.

핵연료주기 분석은 전략적으로 기술적 분석, 국내외 이해관계, 국가 에너지 프로그램과 연계되어야 한다. 이를 위해 다양한 핵연료주기를 비교하여 제시된 평가 지표에 따라 분석하는 연구는 트레이드 연구 방법을 적용하여 수행할 수 있다. 본 연구를 통한 조사 분석 결과 핵연료주기 분석 전략과 함께 방법적 측면에서 트 레이드 연구가 선진 핵연료주기 도출에 활용될 수 있을 것으로 파악되었다. 트레이드 연구에 필수적인 평가 지표를 선정하고 각 지표별 핵연료주기에 대한 정보를 얻기 위해서는 기술성숙도 분석 방법과 핵연료주기 시 뮬레이터를 활용할 수 있을 것으로 제시하였다. 이들은 핵연료주기의 기술성, 경제성, 환경영향성 등을 비교 평가하여 기술개발을 위한 방향을 제시하고 체계적인 선진 핵연료주기 도출 및 실현에 기여할 것이다.

중심단어 : 핵연료주기 분석, 선진 핵연료주기, 트레이드 연구, 기술성숙도분석, 핵연료주기 시뮬레이터

\section{I. 서 론}

시스템 분석(system analysis)은 대상 시스템의 정의와 시 스템 분석의 목적에 따라 여러 분야에서 다양하게 활용되고 있다. 원자력 분야에서 원자로를 시스템으로 설 정한다면 노 물리, 원자로 설계 등이 시스템 분석의 대상이 될 수 있으며 핵연료주기를 분석 대상으로 고려할 경우에는 우라늄의 채광 에서 사용후핵연료의 재순환 또는 직접처분에 이르는 원자력 시스템을 따라 움직이는 핵연료로서 우라늄의 주기가 분석의 핵심이 될 수 있다. 따라서, 시스템 분석을 위해서는 분석 대 상 시스템의 범위를 정의하고 분석의 목적을 명확히 하는 것 이 가장 중요한 첫 단계라 할 수 있다.

선진 핵연료주기 개발을 목적으로 시스템 분석 기술을 적 용하면 폭넓은 핵연료주기 개념을 고려하여 분석함으로서 선 진 핵연료주기 기술 완성에 필요한 기술 개발 비용을 절감하 고 기술 개발 과정과 결과를 체계화할 수 있기 때문에 시스템 분석 기술 자체가 중요한 연구 주제이다. 분석 기술의 개발과 적용으로 획득한 결과를 이용하면 선진 핵연료주기 개발 목 표를 보다 원활히 달성할 수 있게 된다. 보다 구체적으로는 핵연료주기 시스템 분석으로 다양한 핵연료주기를 구성하는 세부 기술들의 개발 목표를 정의하고 신뢰성 있는 기술적 대 안들을 분석하고 궁극적으로 분석된 대안들이 목표에 부합되 는지를 판단할 수 있게 된다.

이와 같은 인식을 바탕으로 미국에서는 선진 핵연료주기 프로그램에 시스템 분석을 중요한 연구 항목으로 선정하였으 며 다른 연구 항목들을 통합할 수 있도록 선진 핵연료주기 프 로그램 구성에서 시스템 분석을 중앙에 배치시켜 연구 개발 을 추진하고 있다. 미국의 AFCI(Advanced Fuel Cycle Initiative) 프로그램에서는 시스템 분석(Systems Analysis)을
핵변환 연료 (Transmutation Fuel), 분리 및 폐기물 (Separations and Waste Forms), 고속로(Fast Reactors), 안 전조치(Safeguards)와 함께 5개의 연구 분야 중 하나로 선정 하였으며 이를 4 개의 타 분야를 연결하는 축으로 설정하여 프로그램을 추진하였다[1].

2006년 2월 미국 에너지부(DOE: Department of Energy) 가 사용후핵연료를 핵비확산성 공정으로 처리한 후 얻어지는 초우란 원소들(TRUs: Transuranics)을 연소로에서 연료로 활 용하여 재순환시키는 전략을 담은 GNEP(Global Nuclear Energy Partnership) 프로그램을 발표한 후, 시스템 분석 연 구는 근시일 내에 가장 실현 가능한 시스템들의 거동과 상호 작용을 이해하기 위한 연구에 초점이 맞추어졌다. 그러나 이 와 같은 연구 방향으로는 GNEP 프로그램을 위한 중요 정보 들을 얻을 수는 있었으나 이는 시스템 분석을 단기간의 목표 설정을 위해 활용함으로서 시스템 분석이 갖고 있는 장점인 기술과 시점에 따라 다양한 대안들을 분석하여 전략적이며 예측적인 결과를 얻을 수 있는 특성을 최대한 활용하지 못한 측면이 있었다.

이 후, 미국은 2009년 국내적으로 AFCI/GNEP 프로그램을 FCR\&D(Fuel Cycle Research \& Development) 프로그램으로 재편하며 유카산 처분장 활용과 근시일 내 도입 가능한 기술 개발이라는 기존의 연구 방향에서 저장, 처리 및 처분 등 정 책 방향에 제한이 없으며 보다 장기적이고 목표 지향적이며 과학적 접근에 기반하는 연구 개발 프로그램을 추진하도록 방향을 전환하였다. 이에 따라 시스템 분석 연구 역시 장기적 이고 과학적인 연구를 위한 정보와 지표 제공을 위한 방향으 로 전환되었다[2]. FCR\&D 프로그램은 Fig. 1[3]과 같이 핵변 환 기술, 분리 및 폐기물, 연료 자원 등의 6개 연구 분야와 함 께 시스템 분석 연구를 추진하여 타 연구 분야를 통합할 수 


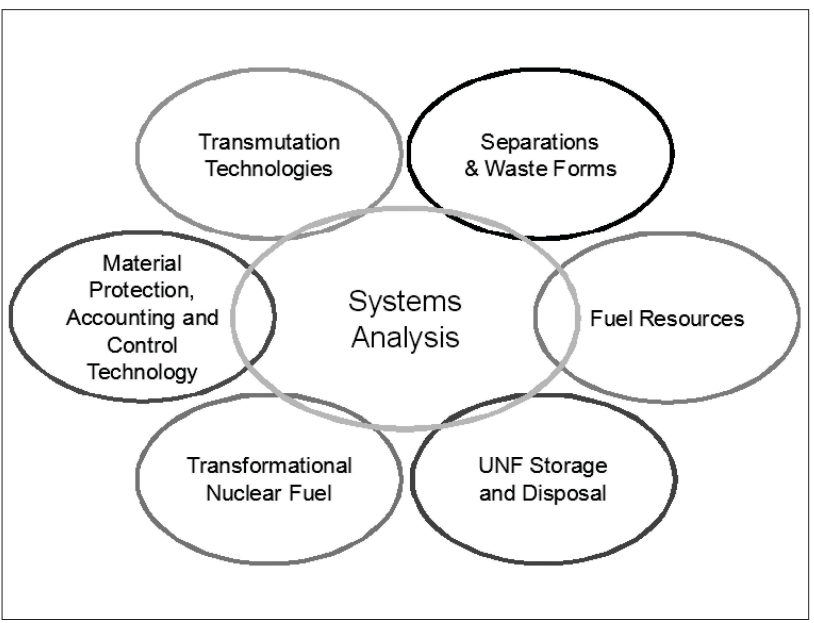

Fig. 1. U.S. FCR\&D programs.

있도록 구성하였다.

FCR\&D 분야에서 DOE는 2011 회계연도 연구 예산으로 2010년 \$136백만에서 약 48\% 대폭 증액된 \$201백만을 요청 하였으며 이 중 $\$ 15.7$ 백만을 시스템 분석 및 통합 연구 분야 로 책정하여 시스템 분석 연구를 추진하고 있다[4]. 시스템 분 석 및 통합 연구를 통해 프로그램 가치와 기술 요건을 개발하 고, 가장 중요한 영향을 끼치는 시스템 요소를 인식하고, 프 로그램 목표 달성을 위해 시스템 엔지니어링과 기술 통합 방 법을 활용하여 진행되는 R\&D와 격차를 판단하고, 핵연료 주 기 시스템 분석과 관련된 데이터 분석 시스템을 개발 관리하 고, 전략적 계획과 정책 개발을 지원하기 위한 정보를 제공하 게 된다.

국내에서도 원자력 중장기 연구 개발 사업의 일환으로 핵 연료주기 시스템 분석 연구가 진행[5, 6]되고 있으나 시스템 분석이 대상으로 하는 다양한 분야와 연구를 통해 얻을 수 있 는 보다 가치 있는 결과를 지원할 수준의 예산과 인력은 확보 하지 못한 상황이다. 그러나, 시스템 분석 기술 개발을 국내 에서 연구개발되고 있는 핵연료주기 기술을 중심으로 집중한 다면 현재 국내에서 수행되고 있는 선진 핵연료주기 기술 개 발 연구를 통합하여 분석하고 타 핵연료주기와 비교 평가함 으로서 연구의 방향을 제시하고 연구 개발의 논리를 개발할 수 있을 것이다.

본 연구에서는 선진 핵연료주기 개발을 위해 시스템 분석 연구가 수행할 수 있는 방법적 틀을 정리하고 방향을 제시함 으로서 시스템 분석 연구의 활용성을 제고하고자 하였다. 이 를 위해 시스템 분석의 전략에 대해 기술하였으며 전략 수행 을 위해 특징적으로 핵연료주기 분석에 사용될 수 있는 방법 들을 설명하였다.

\section{II. 시스템 분석 전략}

핵연료주기 시스템 분석 방법을 예측을 위한 전략적 도구 로 활용하면 정책 결정을 위해 다양한 핵연료주기들의 거동 과 영향을 이해할 수 있다. 분석을 통해 얻어진 결과들은 $\mathrm{R \& D}$ 결과를 평가하고 기술 개발의 방향을 제시하며 전체적 인 시스템의 요건들과 함께 시스템을 구성하고 있는 다양한 개별 요소들에 필요한 요건들의 개발에 활용된다. 또한, 이러 한 결과들로부터 핵연료주기에 관련된 규제 구조의 변화와 같은 정책 결정을 위한 정보를 얻을 수 있다. 시스템 분석 기 술을 최대한 활용하기 위해서 시스템 분석 연구는 관련된 연 구 프로그램들과 확고히 연계되어야 하며 전체 에너지 정책 과 결부된 보다 폭넓은 이슈들에 정보를 제공해야 한다.

선진 핵연료주기 개발을 위해 핵연료주기 시스템 분석 연 구는 핵주기 기술 요건들을 분석 평가하고 국내외 이해당사 자들의 요구 조건들을 조사하는 한편 국가 원자력 정책 수행 을 목표로 설정해야한다. 핵연료주기 시스템 분석으로 얻어 진 결과는 대안 도출에 활용되며 이를 통해 Fig. 2와 같이 연 구개발 방향을 설정할 수 있게 된다. 연구개발의 결과는 다시 핵연료주기 분석을 위한 입력 자료에 반영되어 기술 발전에 대한 이해당사자들의 반응, 원자력 정책의 수정 등이 지속적 으로 공급되어야 한다.

\section{가. 핵연료주기의 기술적 분석}

핵연료주기는 개방형 또는 순환형과 같이 다양한 대안들 이 고려될 수 있다. 이 중 일부는 오랜 기간 많은 연구가 진 행된 것들도 있으나 아직도 많은 분야에서 기술적 검토가 완료되지 못한 부분이 있다. 한편 상대적으로 연구가 많이 진행된 분야에서 조차도 핵연료주기를 둘러싼 기술적, 사회 적, 경제적 환경들과 같은 대내외 여건의 변화에 따라 해당 기술들이 재분석 또는 재평가 되어야하는 상황은 항상 발생 한다.

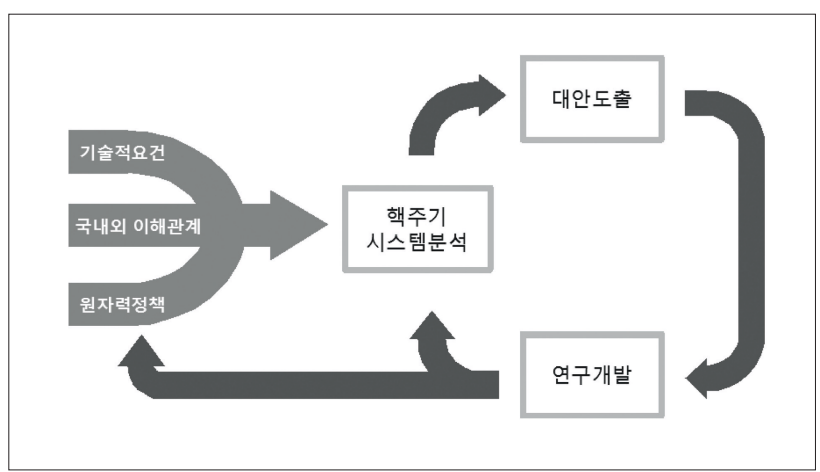

Fig. 2. Schematic description of NFC analysis strategy. 
핵연료주기 기술들의 분석을 위해 수행해야하는 첫 단계 는 대안들이 무엇이며 각각의 장단점은 어떤 것인지 분석하 는 것이다. 이를 위해서는 핵연료주기를 실행하기 위한 다 양한 세부 기술들의 집합들을 평가할 필요가 있다. 기존 정 보들을 수집하고 대내외 환경 변화에 따라 수집된 정보들이 여전히 적합한지 평가해야 한다. 기존의 평가 결과들은 평 가 당시 고려하지 못했던 새로운 정보와 기술의 발전에 의 해 더 이상 유효하지 않을 수도 있다. 시스템 분석으로 다른 연구 분야에서의 결과를 받아 기존 정보와 새로 개발된 정 보들을 기초로 기술적 대안들을 추려나가야 한다. 이와 같 은 업무는 새로운 정보들이 추가됨에 따라 계속 진행된다. 의미 있고 실행 가능한 핵연료주기 도출을 위해서는 다층적 모델링 기법이 다양한 핵연료주기 대안 분석에 사용되어야 하며 전체적인 에너지 정책 개발 측면에서 접근해야 한다. 다층적 모델링 기법에서는 최하단에 각 핵연료 주기 기술에 대한 모델을 놓고 상층으로 올라감에 따라 시스템 분석 대 상을 점차 확대하여 모델링 한 후 상층과 하층 사이에 유기 적으로 데이터를 교환하여 전체 시스템을 분석하게 된다.

\section{나. 국내외 이해관계 분석}

원자력 에너지는 전세계적인 온실 가스 감축을 위해 필수 적인 기술이다. 현재 미국에서 생산되는 온실 가스를 발생 시키지 않는 전력 생산량의 약 $70 \%$ 는 원자력 발전으로부터 얻어지고 있다. 전세계적인 관점에서, 온실 가스 배출량을 줄이고 기후 변화 방지를 위해 노력하는 한편 지속적인 성 장을 위한 자국의 에너지원 확보 측면에서 원자력 에너지의 역할은 증대될 것으로 예상된다.

원자력과 관련된 가장 큰 이슈들은 1) 경제성, 2) 안전과 핵비확산성, 3) 사용후핵연료 관리와 폐기물 처분이다. 경제 성은 우라늄 자원의 유한한 특성에 따라 우라늄 자원의 가 용성과 핵주기 시설들의 건설 운영에 대한 비용 분석 등이 필수적으로 수반되어야 한다. 핵주기 시설 및 기술의 안전 성과 핵비확산성 평가를 위해서는 국가 안전 기준과 IAEA 안전 기준을 비롯하여 안전조치 기술을 종합 분석 평가하여 야 한다. 사용후핵연료 관리와 폐기물 처분은 가장 어려운 분야로 사용후핵연료 건식저장, 재활용 기술과 폐기물 처분 기술과 함께 사회적 이해 관계를 분석해야 한다.

\section{다. 국가 에너지 프로그램과 연계}

국가 에너지 수급 정책과 미래 전략을 반영하여 핵연료주 기 옵션들에 대한 원자력 에너지 전개의 의미를 평가하는 것은 매우 중요하다. 2010년 12월 확정 공고된 제 5 차 전력
수급계획에 따르면 설비용량 기준으로 2010년 전력구성으 로 $24.8 \%$ 를 차지하고 있는 원자발전 용량은 2024년에 이르 러서는 그 비중이 $31.9 \%$ 로 확대될 전망이다. 발전량을 기준 으로 하면 2024년에는 $48.5 \%$ 의 전력이 원자력 발전을 통해 생산될 계획이다. 이러한 원자력 확대 정책을 기초로한 발 전원 구성에 대한 계획은 전력수요에 대한 원자력 발전의 변동성이 크지 않음을 고려한 결과이다.

이와 같은 계획이 중단기 핵연료주기 분석의 주된 논의 사항에 포함되어야만하며 국가 에너지 프로그램이 연계되 어 거시적 핵연료주기 분석의 목표에 반영 될 것이다. 더 나 아가 이러한 평가들은 장기적으로 미래에 중요하게 대두 될 수 있는 고속로, 고온 가스 냉각로와 같은 제 4 세대 원자로와 함께 초고연소도 연료 등의 진보된 경수로 기술도 포함할 수 있을 것이다.

\section{III. 시스템 분석 방법}

일반적인 기술 분석에서부터 전체적인 모델링 및 시뮬레 이션까지 핵연료주기 시스템 분석에는 다양한 방법들이 적 용 수준에 따라 상호 보완적으로 사용될 수 있다. 핵연료주 기 시스템 분석의 주된 목적 중 하나를 핵연료주기 기술개 발을 위한 요건 도출과 도출된 요건 충족을 위한 기술개발 방향 설정과 대안 핵연료주기별 비교 평가로 규정한다면 다 양한 분야에서 시스템 분석 방법으로 사용되는 방법인 트레 이드 연구를 핵연료주기 기술에 적용할 수 있다.

트레이드 연구는 개발된 평가 지표들과 가중치를 결정하 여 종합하여 최종적으로 우수한 대안을 도출하는 연구이며 각 지표별 비교 평가에도 활용될 수 있다. 핵연료주기 분석 에 이 방법을 활용하기 위해서는 시스템에 적합한 평가 지 표를 우선적으로 설정해야 하며 각 지표별로 비교 대상 핵 연료주기를 객관적으로 평가해야 한다. 핵연료주기 비교 지 표를 기술성, 경제성, 환경영향성 등으로 설정한다면 TRL 분석법 및 핵주기 시뮬레이션 방법이 이를 위해 활용될 수 있다.

\section{가. 트레이드(trade) 연구의 핵연료주기 분석 활용 (1) 트레이드 연구 개요}

트레이드 또는 트레이드오프(trade-off)의 의미를 사전적 으로 살펴보면 두 개 또는 그 이상의 목표 중 하나를 달성하 기 위해서 다른 목표의 달성이 늦어지거나 희생되는 경우를 의미한다. 사용되는 주제에 따라 다양하게 표현되고 있으며 경제학적으로는 길항관계 또는 상충관계로 번역되기도 한 
다. 공학적으로는 적절한 표현이 아직 나타나지 않았으며 트레이드 또는 트레이트오프와 같이 원어를 사용하는 경우 가 대부분이다.

트레이드 연구는 시스템 엔지니어링(SE : system engineering)의 요소로, 제안된 실행 가능한 방안의 집합에 서 가장 균형 잡힌 기술적 방안을 도출하는 연구이다[7]. 트 레이드 연구는 대상 프로그램의 전주기 중 어느 단계에서든 결정을 해야 되는 상황에서 합리적인 판단을 위한 연구로 이 과정을 통해 프로젝트 목적 달성을 위해 정의된 지표들 의 항목으로 다양한 시스템 대안들을 정성 또는 정량 (또는 정성 정량의 모든 측면에서) 평가할 수 있다.

트레이드 연구는 Fig. 3과 같이 다양한 시스템 엔지니어링 의 요소들로부터 얻어진 정보를 입력 받아 대안을 평가하고 민감도를 분석하여 결과물을 제공하는 역할을 한다. 이를 위해 트레이드 연구는 기술, 비용, 일정의 측면에서 도출된
요건들을 만족시키기 위해 프로그램 전주기의 여러 단계에 서 수행되며 다양한 시스템 대안들을 비교하기 위한 지표들 (metrics)을 객관적으로 제공한다.

\section{(2) 트레이드 연구 절차}

트레이드 연구는 다음과 같은 절차로 구성되어 있다. 이 러한 단계들은 차례차례 실행되지는 않으며 평가 기준의 정 의와 같이 어떤 단계들은 대안들이 정의되고 평가됨에 따라 반복적으로 수행된다.

- 범위 및 기본 규칙 결정

- 연구의 범위와 방법을 확립하기 이전에 달성되어야 하는 요건들과 트레이드 연구의 특정한 목표 결정

- 시스템의 목표와 목적을 정의하고 제약조건을 파악

- 트레이드 연구의 주요 마일스톤을 확인하고 달성할 수 있는 일정을 개발

- 평가기준, 가중 인자 정의 및 대안 평가 (Fig. 4)

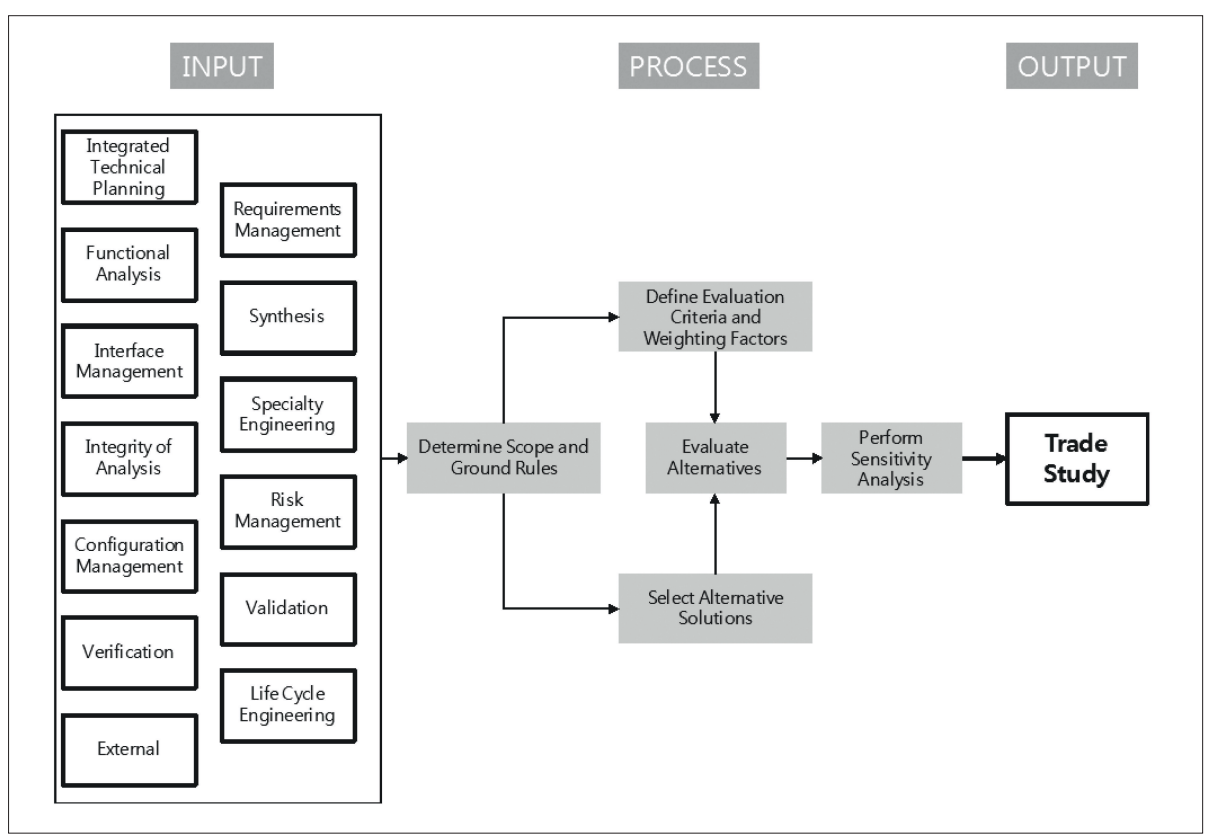

Fig. 3. Procedures of trade study.

\begin{tabular}{|c|c|c|c|c|c|c|c|c|}
\hline & \multirow{2}{*}{\multicolumn{2}{|c|}{$\begin{array}{c}\text { Decision Factor } 1 \\
\text { Weight }=3\end{array}$}} & \multirow{2}{*}{\multicolumn{2}{|c|}{$\begin{array}{c}\text { Decision Factor } 2 \\
\text { Weight }=1.5 \\
\end{array}$}} & \multirow{3}{*}{$\begin{array}{c}\ldots \\
\ldots \\
\ldots\end{array}$} & \multirow{2}{*}{\multicolumn{2}{|c|}{$\begin{array}{c}\text { Decision Factor } \mathrm{n} \\
\text { Weight }=2.5\end{array}$}} & \multirow{3}{*}{$\begin{array}{c}\text { Total } \\
\text { Weighted } \\
\text { Score }\end{array}$} \\
\hline & & & & & & & & \\
\hline & Score & $\begin{array}{c}\text { Weighted } \\
\text { Score }\end{array}$ & Score & $\begin{array}{c}\text { Weighted } \\
\text { Score }\end{array}$ & & Score & $\begin{array}{l}\text { Weighted } \\
\text { Score }\end{array}$ & \\
\hline Alternative 1 & 7 & 21 & 4 & 6 & $\ldots$ & 8 & 20 & 47 \\
\hline Alternative 2 & 8 & 24 & 10 & 15 & $\ldots$ & 10 & 25 & 64 \\
\hline$\ldots$ & $\ldots$ & $\ldots$ & $\ldots$ & $\ldots$ & $\ldots$ & $\ldots$ & $\ldots$ & $\ldots$ \\
\hline Alternative $\mathrm{n}$ & 10 & 30 & 5 & 7.5 & $\ldots$ & 12 & 30 & 67.5 \\
\hline $\begin{array}{l}\text { Alternative } \\
n+1\end{array}$ & $\cdots$ & $\cdots$ & $\cdots$ & $\cdots$ & $\cdots$ & $\cdots$ & $\cdots$ & $\cdots$ \\
\hline
\end{tabular}

Fig.4. Illustration of evaluation table used in trade study. 
- 요건 분석에 기반한 평가기준 정의

- 평가기준의 상대적 가중치 결정

- 평가기준과 평가되는 대안으로 구성된 점수표 준비

— 점수표의 각 요소들에 점수를 매기기 위한 방법 결정

- 각 대안을 대상으로 각 평가기준에 대한 점수화

- 각 평가 기준에 가중치 부여 및 가중화 평가 점수 산출 이와 같은 평가 기준으로는 시스템에 따라 개발비, 전주 기 비용, 기술 성숙도, 일정 위험도 등이 고려될 수 있다.

- 대안 선정 및 평가

— 선정된 실행 가능한 대안들의 상세 평가

- 높은 가중치를 받았으나 선정되지 못한 대안들의 확인

- 평가 기준과 별도로 비용 요소들의 평가

- 민감도 분석

- 다양한 가중치에 따른 가중 점수의 영향 평가

- 점수 변화에 대한 가중 점수의 민감도 평가

- 각 기준에서 평가된 점수와 가중치의 범위 기록

— 통계적 분석으로 평가의 정확성 제시

- 결과 검토 및 결론 도출

\section{(3) 핵연료주기 트레이드 분석 지표}

트레이드 연구를 사용하여 핵연료주기를 분석한 연구는 미국에서 $\mathrm{AFCI}$ 프로그램에서 비교적 활발히 진행되었다[8]. 이와 같은 전체적인 국가 프로그램 이외에도 핵연료주기 시 나리오들에 대한 트레이드 연구는 최근 활발히 적용되고 있 다[9]. 특정한 핵연료주기의 특성을 비교 평가하기 위해 사용 된 트레이드 연구에서 Tendall과 Binder[9]는 Table 1과 같은 8 개의 핵연료주기 비교 평가 기준을 제시하였다. 이와 같은 평가 기준을 설정하고 최종적으로는 Fig. 4와 같은 형태로 가 중치를 부여하여 비교 분석함으로서 핵연료주기별 트레이드 분석을 수행할 수 있으며 선진 핵연료주기 구현이라는 목표 달성을 위해 보다 체계적인 형식을 얻을 수 있게 된다.

\section{나. 기술성숙도(TRL: Technology Readiness Level) 분석}

\section{(1) 기술 성숙도 분석 개요}

기술성숙도(TRL: Technology Readiness Level) 분석법은 특정기술의 성숙도 평가와 이종 기술간의 성숙도 비교에 활 용될 수 있는 체계적인 측정 방법이다. 1980년대 후반 미국 NASA에서 우주산업의 위험도 관리 목적으로 개발되었으며 이후 민간 R\&D 프로그램에 확대 적용되고 있다. TRL에서는 실제규모(full-scale)로 구현할 수 있는 기술 성숙도에 대비 하여 상대적인 기술 수준을 평가하는 방법으로 일반적으로 기초 이론 단계인 1 단계에서 운영단계인 9단계까지를 기준
으로 기술 수준을 정의하여 분석하고 있다(Fig. 5).

TRL의 각 단계는 분석 대상 기술에 따라 적절하게 정의되어 이용될 수 있으며 일반적으로 Table 2 와 같이 3 개의 범주로 구 분되어 사용된다. TRL은 기술 성숙도가 가장 낮은 TRL 1 에서 가장 높은 TRL 9의 범위로 구성한다. 예를 들어, TRL 1 로 평가 받은 기술은 기술 성숙도가 가장 낮아 과학적 연구가 응용 연

\section{Table 1. Metrics of NFC analysis.}

\begin{tabular}{|c|c|c|}
\hline \multicolumn{2}{|c|}{ Criteria } & Definition \\
\hline \multirow{5}{*}{$\begin{array}{c}\text { environmental } \\
\text { criteria }\end{array}$} & saved uranium & $\begin{array}{l}\text { percentage of reduction of uranium demand } \\
\text { compared to current situation }\end{array}$ \\
\hline & waste production & $\begin{array}{l}\text { increase/decrease of waste quantity, combined } \\
\text { with increase/decrease of waste radioactivity }\end{array}$ \\
\hline & energy demand & total energy requirement of processes \\
\hline & chemical risks & $\begin{array}{l}\text { increased/decreased use of chemicals (e.g., } \\
\text { strong acids) }\end{array}$ \\
\hline & radiation risks & $\begin{array}{l}\text { based on increase/decrease of waste } \\
\text { radioactivity, and of production, transport and } \\
\text { manipulation of radioactive wastes, for status } \\
\text { quo: assessment according to the isotopic } \\
\text { content of the flows, and the degree of } \\
\text { security of the processes }\end{array}$ \\
\hline \multirow{2}{*}{$\begin{array}{l}\text { economic } \\
\text { criteria }\end{array}$} & operation costs & $\begin{array}{l}\text { increase/decrease of cost of nuclear energy } \\
\text { production compared to current situation }\end{array}$ \\
\hline & investment costs & $\begin{array}{l}\text { investments required for implementing the } \\
\text { scenario }\end{array}$ \\
\hline social criteria & proliferation risks & $\begin{array}{l}\text { based on isotopic content of flows, and state } \\
\text { of separation of problematic isotopes from } \\
\text { other components }\end{array}$ \\
\hline
\end{tabular}

Table 2. Definition and criteria of TRL

\begin{tabular}{|c|c|c|}
\hline TRL & 범 주 & 내 용 \\
\hline 9 & \multirow{3}{*}{$\begin{array}{c}\text { 성능 입증 } \\
\text { (Proof of } \\
\text { Performance) }\end{array}$} & 성공적인 운전을 통한 실제 시설 증명 \\
\hline 8 & & 원형(prototype) 시설 완성 및 시험과 시연을 통한 검증 \\
\hline 7 & & 원형(prototype) 환경에서 원형(prototype) 시스템 시연 \\
\hline 6 & \multirow{3}{*}{$\begin{array}{l}\text { 원리 입증 } \\
\text { (Proof of } \\
\text { Principle) }\end{array}$} & 관련 환경에서 시스템 모델 또는 원형(prototype) 시연 \\
\hline 5 & & 관련 환경에서 구성 요소 및 지원 요소 검증 \\
\hline 4 & & $\begin{array}{l}\text { 실험실 환경에서 구성 요소 및 실험대 규모 (bench-scale) } \\
\text { 검증 }\end{array}$ \\
\hline 3 & \multirow{3}{*}{$\begin{array}{c}\text { 개념 개발 } \\
\text { (Concept } \\
\text { Development) }\end{array}$} & 주요 기능 및 개념 입증을 위한 분석적 실험적 시연 \\
\hline 2 & & 기술 개념 및 응용 방법 구상 \\
\hline 1 & & 기본 원리 관찰 및 구상 \\
\hline
\end{tabular}

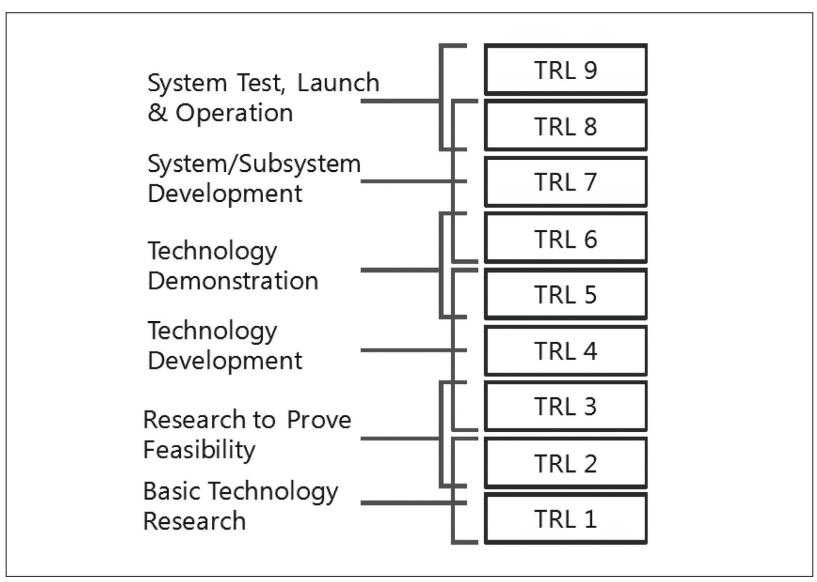

Fig. 5. Structure of general TRL. 
구 개발에 이전되기 시작하는 단계이다. 기술이 TRL 9 단계에 이르기 위해서는 초기 응용 개념이 공식화(formulation)되고, 원리가 입증되고, 실험실 환경과 실제 환경에서 실증되고, 시 스템으로 통합되어야 한다. 최종 개발 단계인 TRL 9에서는 기 술의 목표 조건 하에서 기술이 운영되어야 한다.

$\mathrm{TRL}$ 분석은 기술 이전에 대한 위험 관리 측면에서도 유용 하게 활용되며 TRL 수준이 높아지면 Fig. 6와 같이 불확실 성에 의한 위험은 감소하게 된다. 일반적으로 특정 기술이 TRL 7에 다다르면 위험을 감수할만하며 공학적 단계를 시작 할 수 있을 것으로 여겨진다. TRL 분석은 최종 사용자로의 기술 이전을 위해 프로그램의 위험과 잠재성에 대한 척도를 제공한다. 예를 들어, TRL 1 과 같이 낮은 기술은 더 많은 투 자가 필요하고 높은 위험을 나타내는 반면 TRL 7과 같이 높 은 기술 수준은 기술 개발이 성숙되어 많은 성과를 얻을 수 있으며 감수해야할 위험도가 낮다는 것을 의미한다.

최근에는 정량적으로 TRL을 분석하기 위해 TRL 계산기[10] 가 개발되고 있다. TRL 분석을 위해 Microsoft ${ }^{\circledR}$ Excel $^{\circledR}$ 을 사용 하여 기술에 대한 일련의 질문들을 하고 이에 대한 답을 하는 형식으로 각 단계에 대한 기술 성숙도를 반복적으로 측정할 수 있는 도구를 제공하고 있다. 미국 DOE에서는 이를 수정 활 용하여 폐기물처리 시설에 대한 TRL 측정에 활용한 바 있다 [11]. DOE는 Table 3[11]과 같은 최상위 질문을 시작으로 하여 각 단계에서 기술적 관점과 프로그램 관점에서 정량 또는 정 성적인 질문을 하여 TRL을 계산하였다. 예로 Table 4[11]는 TRL 1에 대한 질문들을 보여주고 있다.

이와 같은 TRL 측정 계산기 방법은 핵연료주기 분야에 직접 활용된 예는 아직 없다. 그러나, 기본적인 TRL 개념을 이해하 고 있다면 Table 3 및 Table 4에서 보여지는 질문들을 수정하 여 활용하여 보다 체계적인 핵연료주기 TRL 측정 방법을 개발 할 수 있을 것으로 예상된다.

\section{(2) 핵연료주기 TRL 분석}

원자력 분야 기술 분석에 사용된 TRL 방법은 여러 곳[12, 13]에서 찾을 수 있으나 전체적인 핵연료주기 시스템 분석

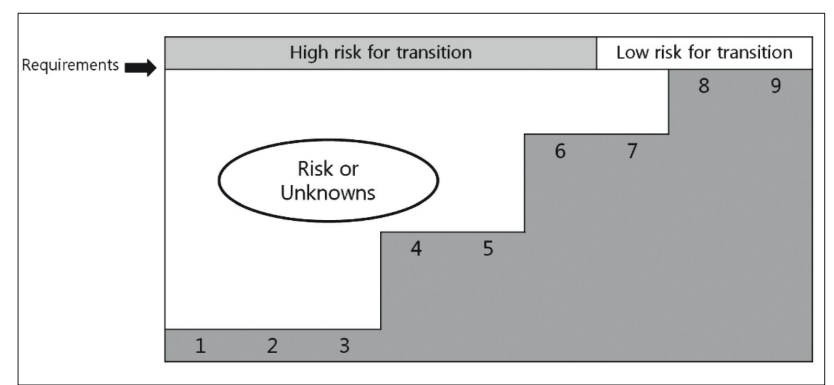

Fig. 6. Technology transition risk with TRL
Table 3. Top level questions for TRL determination.

\begin{tabular}{|c|l|}
\hline TRL & \multicolumn{1}{|c|}{ Top Level Question } \\
\hline TRL 9 & $\begin{array}{l}\text { Has the actual equipment/process successfully operated in the full } \\
\text { operational environment (Hot Operations)? }\end{array}$ \\
\hline TRL 8 & $\begin{array}{l}\text { Has the actual equipment/process successfully operated in a limited } \\
\text { operational environment (Hot Operations)? }\end{array}$ \\
\hline TRL 7 & $\begin{array}{l}\text { Has the actual equipment/process successfully operated in the relevant } \\
\text { operational environment (Cold Operations)? }\end{array}$ \\
\hline TRL 6 & $\begin{array}{l}\text { Has prototypical engineering scale equipment/process testing been } \\
\text { demonstrated in a relevant environment? }\end{array}$ \\
\hline TRL 5 & $\begin{array}{l}\text { Has bench-scale equipment/process testing been demonstrated in a } \\
\text { relevant environment? }\end{array}$ \\
\hline TRL 4 & $\begin{array}{l}\text { Has laboratory scale testing of similar equipment systems been } \\
\text { completed in a simulated environment? }\end{array}$ \\
\hline TRL 3 & $\begin{array}{l}\text { Has equipment and process analysis and proof of concept been } \\
\text { demonstrated in a simulated environment? }\end{array}$ \\
\hline TRL 2 & Has an equipment and process concept been formulated? \\
\hline TRL 1 & $\begin{array}{l}\text { Have the basic process technology process principles been observed } \\
\text { and reported? }\end{array}$ \\
\hline
\end{tabular}

Table 4. Detailed questions for TRL 1.

\begin{tabular}{|c|c|c|c|}
\hline $\begin{array}{l}\mathrm{H} / \mathrm{S} / \\
\text { Both }\end{array}$ & Cat. & $\begin{array}{c}\% \\
\text { Complete } \\
\end{array}$ & Criteria \\
\hline $\mathrm{B}$ & $\mathrm{T}$ & & "Back of envelope" environment \\
\hline B & $\mathrm{T}$ & & $\begin{array}{l}\text { Physical laws and assumptions used in new technologies } \\
\text { defined }\end{array}$ \\
\hline S & $\mathrm{T}$ & & $\begin{array}{l}\text { Have some concept in mind for software that may be } \\
\text { realizable in software }\end{array}$ \\
\hline$S$ & $\mathrm{~T}$ & & Know what software needs to do in general terms \\
\hline B & $\mathrm{T}$ & & Paper studies confirm basic principles \\
\hline S & $\mathrm{T}$ & & $\begin{array}{l}\text { Mathematical formulations of concepts that might be } \\
\text { realizable in software }\end{array}$ \\
\hline S & $\mathrm{T}$ & & $\begin{array}{l}\text { Have an idea that captures the basic principles of a } \\
\text { possible algorithm }\end{array}$ \\
\hline B & $\mathrm{P}$ & & $\begin{array}{l}\text { Initial scientific observations reported in journals/ } \\
\text { conference proceedings/technical reports }\end{array}$ \\
\hline $\mathrm{B}$ & $\mathrm{T}$ & & Basic scientific principles observed \\
\hline B & $\mathrm{P}$ & & $\begin{array}{l}\text { Know who cares about the technology; e.g., sponsor, } \\
\text { money source }\end{array}$ \\
\hline $\mathrm{B}$ & $\mathrm{T}$ & & Research hypothesis formulated \\
\hline B & $\mathrm{P}$ & & $\begin{array}{l}\text { Know who will perform research and where it will be } \\
\text { done }\end{array}$ \\
\hline \multicolumn{4}{|c|}{$\begin{array}{l}\text { H: Hardware element, contains no appreciable amount of software } \\
\text { S: Completely a software system } \\
\text { B: Some hardware and software } \\
\text { T: Technology, technical aspects } \\
\text { M: Manufacturing and quality } \\
\text { P: Programatic, customer focus, documentation }\end{array}$} \\
\hline
\end{tabular}

에 활용된 TRL 분석 방법은 미국 $\mathrm{GNEP}$ 의 기술 개발 계획 [14]에 비교적 잘 정리되어 있다. 여기서는 GNEP에서 수행 한 TRL 분석을 제시함으로서 선진 핵연료주기 개발을 위한 핵연료주기 시스템 분석에서의 TRL 방법 활용에 대해 기술 하도록 하겠다.

GNEP 기술 개발 계획에서는 1) 경수로 사용후핵연료 처 리, 2) 폐기물 형태 개발, 3) 고속로 사용후핵연료 처리, 4) 연료 제조, 5) 연료 성능 분야에서 $\mathrm{TRL}$ 을 제시하고 미국의 기술 수준을 평가하였다.

GNEP 프로그램에서는 경수로 사용후핵연료 순환을 위한 기준 처리 기술로 $\mathrm{UREX}+1 \mathrm{a}$ 를 선정하였다. UREX+1a는 $\mathrm{UREX}+1$ 에서 $\mathrm{UREX}+4$ 로 이어지는 UREX 계열의 습식기술 들 중 하나로 $\mathrm{U}$ 을 고순도로 분리하고 모든 TRU를 군분리하 
여 회수하는 공정이다. UREX+1a 공정은 네 개의 용매 추출 공정과 한 개의 이온 교환 공정으로 구성되어 있다. 공정 단 계에 따라 (1) U 및 Tc 회수(UREX), (2) Tc에서 U 분리(이 온 교환), (3) Cs 및 $\mathrm{Sr}$ 회수(CCD-PEG), (4) 금속 분열생성 물의 란타나이드 및 TRU 원소들로부터 분리(TRUEX), (5) 란타나이드 회수(TALSPEAK), (6) Pu, Np, Am, 및 Cm 회수 (TALSPEAK)가 진행된다. 실제 $34 \mathrm{GWd} / \mathrm{t}$ 연소도 BWR과 $76 \mathrm{GWd} / \mathrm{t}$ PWR 사용후핵연료 $1 \mathrm{~kg}$ 을 사용한 실험실 규모 실험에서 $\mathrm{UREX}+1 \mathrm{a}$ 공정으로 Table 5 와 같은 높은 회수율 이 보고되었다[15].

$\mathrm{UREX}+1 \mathrm{a}$ 를 사용한 분리 기술은 사용후핵연료를 대상으 로 벤치규모(bench-scale)에서 실증되었다. UREX 계열 기 술들은 상업적으로 사용되고 있는 PUREX 공정을 수정한 것 이므로 UREX 계열 공정들의 대용량화에 큰 문제가 없을 것 으로 GNEP에서는 판단하였다. 이에 따라 경수로 사용후핵 연료 처리 현 기술 수준을 TRL 5 로 판단하였다.

$\mathrm{UREX}+1 \mathrm{a}$ 공정에서 $\mathrm{U}, \mathrm{TRUs}, \mathrm{Cs} / \mathrm{Sr}$, Tc 및 FPs 등이 생산 물 또는 폐기물 물질흐름으로 발생된다. 폐기물은 일반적으 로 고화되어 처분되며 피복관과 $\mathrm{Tc}$ 는 금속 형태로, 이외 폐 기물들은 안정적인 고체 형태로 전환되어 처분된다. Table 6[15]은 사용후핵연료 $100 \mathrm{t}$ 을 UREX+1a 또는 UREX+3 공정 으로 처리했을 때 발생되는 폐기물 종류와 처분 형태 및 부 피를 표시하고 있다. 사용후핵연료 $100 \mathrm{t}$ 의 포장전 부피인 $45 \mathrm{~m}^{3}$ 을 참조하면 UREX 계열 공정에 의한 폐기물의 양을 비교할 수 있다.

폐기물들을 고화시키는 공정은 폐기물의 종류에 따라 개 념 도출 단계인 공정부터 실제규모로 적용이 가능한 공정까 지 범위가 다양하게 나타나고 있다. 혼합된 TRU의 고화처 리에 대해서는 아직 대용량 실증이 이뤄지지 않았으며 방사 성 물질을 사용하여 벤치규모(bench-scale)의 혼합 TRU 흐 름에 대한 처리 공정이 실증되어야 하는 상황이다. 반면 일 부 배기체 폐기물들은 이미 처리 기술이 개발되어 상용 PUREX 시설에 적용되고 있다. 이와 같이 각 폐기물에 대한 공정 개발 정도를 종합하여 폐기물 형태 개발을 위한 기술 수준을 TRL 4 로 정의하였다.

핵종변환을 위한 고속로 사용후핵연료 처리 공정으로 습 식과 건식 공정을 $\mathrm{GNEP}$ 에서는 모두 고려하였다. 건식 공정 개발 및 실증은 미국의 고속로 프로그램인 EBR-I과 EBR-II 의 일환으로 진행되었었다. 미국 INL에 있는 FCF(Fuel Conditioning Facility)에서 대규모로 건식 기술이 사용되었 다. 초기에 EBR-II/FCF 프로그램의 목적은 금속 연료 고속 증식로를 위한 선진 재순환 핵주기 기술을 개발하는 것이었
으나 1994년 EBR-II가 운전정지되면서 FCF 기술은 EBR-II 연료의 처분을 위한 기술로 방향을 전환하였다. LWR 사용 후핵연료에 적용되는 습식 공정은 금속연료 고속로에는 적 용이 어렵다. 이는 원자로에서 연소하는 동안 연료 메트릭 스에 퍼지게 되는 나트륨을 제거하는데 어려움이 있기 때문 이다. 반면, 산화물 고속로 사용후핵연료는 1980년대 ORNL 에서 Consolidated Fuel Recycle Program으로 실증되어 수 $\mathrm{kg}$ 의 사용후핵연료가 처리되었다. 이 프로그램으로 산화물 고속로 연료의 습식 처리의 가능성이 보여졌으나 LWR 습식 처리와 다른 고속로 연료를 위한 공정 파라메터들에 대한 연구가 필요하다. 결과적으로 습식과 건식 공정 모두 상업 규모로의 확대를 보장할 수 있는 규모로 고속로 사용후핵연 료에서 TRU 군분리에 사용된 예는 없기 때문에 TRL 4 로 판 단하였다.

GNEP의 목적 달성을 위해 TRU를 함께 고속 연소로에서 균질한 노심으로 연소시키는 개념을 우선적으로 고려하고 있으며 TRU 소멸을 위한 핵변환 연료를 사용하는 개념 역 시 고려하고 있다. 그러나 아직까지 마이너 악티나이드를 포함하고 있는 연료가 고속로에서의 사용이 입증된 경우는 없다. 이 분야에 대해서는 타당성 연구의 초기 단계에 있는 것으로 판단하였으며 금속 및 산화물 연료 모두 연구 개발 이 진행되어야할 것으로 제시하였다. 산화물 형태의 연료는 $(\mathrm{U}, \mathrm{Pu}) \mathrm{Ox}$ 의 혼합 산화물로 프랑스, 일본, 러시아에서 조사 된 경험이 있다. 그러나 아직까지 $\mathrm{MA}$ 를 함유한 산화물 연료

Table 5. Recovery efficiencies of UREX +1 a

\begin{tabular}{|c|c|c|}
\hline Element & Recovery Eff. & Remarks \\
\hline Uranium & $99.9992 \%$ & Non-TRU ( $\langle 100 \mathrm{nCi} / \mathrm{g})$ \\
\hline Technetium & $95.5 \%$ & Soluble Tc \\
\hline Cesium & $>99.85 \%$ & \\
\hline Strontium & $99.1 \%$ & \\
\hline Plutonium & $>99.998 \%$ & \multirow{4}{*}{$\begin{array}{l}\text { Total lanthanide content } \\
\text { transuranics }\langle 0.055 \\
(\mathrm{DF}\rangle 2,000)\end{array}$} \\
\hline Neptunium & $>99.992 \%$ & \\
\hline Americium & $>99.97 \%$ & \\
\hline Curium & $>99.9993 \%$ & \\
\hline
\end{tabular}

Table 6. Process waste by UREX $+1 \mathrm{a} /+3$ processing $100 \mathrm{t}$ of $\mathrm{SF}$.

\begin{tabular}{|c|c|c|c|}
\hline Waste Stream & Waste Composition & Category & Volume, $\mathrm{m}^{3}$ \\
\hline Uranium & $\mathrm{U}_{3} \mathrm{O}_{8}$ powder & (Storage) & 18 \\
\hline Cesium/strontium & $\mathrm{Cs} / \mathrm{Sr}$ aluminosilicate & (Storage) & 1.1 \\
\hline Hulls + Tc, sludge & Zr-Fe based alloy & HLW & 0.6 \\
\hline Compacted hulls & Non-TRU Zr & HLW & 6.1 \\
\hline U losses & Borosilicate glass & HLW & $1.0 \sim 3.4$ \\
\hline TRU losses & Borosilicate glass & HLW & 0.06 \\
\hline Iodine & Potassium Iodate & HLW & 0.018 \\
\hline Krypton & Zeolite/aluminosilicate & HLW & 0.014 \\
\hline Tritium & Grout & HLW & $\langle 0.01$ \\
\hline Lanthanide FPs & LABS glass & HLW & 0.31 \\
Carbon-14 & Sodium carbonate & HLW & 0.034 \\
\hline
\end{tabular}


는 개발 초기 단계이며 프랑스의 Phenix 에서 $\mathrm{Pu}, \mathrm{Am}$ 및 $\mathrm{Np}$ 이 함유된 펠렛이 조사된 수준에 있다. 금속 연료는 미국의 EBR-II에서 $\mathrm{U} / \mathrm{Pu} / \mathrm{Zr}$ 의 형태로 상당한 운전 경험이 있으며 IFR 프로그램으로 $\mathrm{Pu}$ 함유 금속 연료의 실험은 완료된 상황 이다. 연료 내 TRU의 제한 조성 범위가 연구되고 있으나 $\mathrm{Cm}$ 에 대한 영향은 아직 알려지지 않았다. 따라서 고속로 연 료 제조 및 성능 TRL에서 TRL 4 로 각각 정의하였다.

GNEP 프로그램에서 TRL 분석법을 이용한 결과는 Fig. 7 과 같이 정리할 수 있다. 이와 같이 TRL 분석 방법을 활용하 면 선진 핵연료 주기 기술 개발 목표를 달성하기 위해 기술 적 간극이 어느 분야에 얼마나 존재하고 있는지를 한눈에 파악할 수 있으며 이를 바탕으로 자원의 배분, 일정 조정 등 과 같은 시스템 엔지니어링 기법들을 활용할 수 있게 된다.

\section{다. 핵연료 주기 시뮬레이션 코드 활용}

핵연료 주기 시뮬레이션을 위해 다양한 기관에서 각자의 목적에 맞춰 다양한 종류의 핵연료 주기 시뮬레이션 코드를 개발하여 사용하고 있다. 주요 시뮬레이션 코드는 Table 7 과 같이 정리할 수 있다.

현재까지 개발된 핵연료 주기 코드들은 다지역 분석, 개 별 동위원소 추적 및 비용 분석들과 같이 필요한 기능 및 성 능을 다양한 범위에서 처리할 수 있다. 그러나, 모든 코드들 이 개발자들의 관심에 따라 핵연료 주기 분석의 특정 부분 에 강조되어 전체를 시뮬레이션하지는 못하고 있다. 예를 들면, 몇몇 코드들은 개별 동위원소 추적은 무시하고 경제

Table 7. Selected NFC simulation codes.

\begin{tabular}{|c|c|c|c|}
\hline Name & Developer & Name & Developer \\
\hline CAFCA & MIT (미국) & GENIUSv1 & INL (미국) \\
\hline COSI6 & CEA (프랑스) & GENIUSv2 & U. of Wisconsin (미국) \\
\hline DANESS & ANL (미국) & NFCSS & IAEA \\
\hline DESAE2.1 & Rosatom (러시아) & NFCSim & LANL (미국) \\
\hline EVOLCODE2 & CIEMAT (스페인) & VISION & ANL/INL (미국) \\
\hline FAMILY21 & JAEA (일본) & & \\
\hline
\end{tabular}

\begin{tabular}{|c|c|c|c|c|c|c|}
\hline \multirow{3}{*}{$\begin{array}{l}\text { Proof of } \\
\text { Performance }\end{array}$} & 9 & & & & & \\
\hline & 8 & & & & & \\
\hline & 7 & & & & & \\
\hline \multirow{3}{*}{$\begin{array}{l}\text { Proof of } \\
\text { Principle }\end{array}$} & 6 & & & & & \\
\hline & 5 & & & & & \\
\hline & 4 & & & & & \\
\hline \multirow{3}{*}{$\begin{array}{c}\text { Concept } \\
\text { Development }\end{array}$} & 3 & & & & & \\
\hline & 2 & & & & & \\
\hline & 1 & & & & & \\
\hline & & $\begin{array}{c}\text { 경수로 SF } \\
\text { 처리 }\end{array}$ & $\begin{array}{c}\text { 폐기물 } \\
\text { 형태 개발 }\end{array}$ & $\begin{array}{c}\text { 고속로 SF } \\
\text { 처리 }\end{array}$ & 연료 제조 & 연료 성능 \\
\hline
\end{tabular}

Fig. 7. Summary of GNEP TRL.
성에 초점을 맞추기도 하고 몇몇은 폐기물 처분 측면에서의 장단점 비교를 위해 상세하게 물질 흐름을 계산하는 반면 비용 분석을 무시하기도 한다. 현재까지는 이들 코드들은 서로 연계될 수 없도록 구성되어 있어 각각의 장점을 살려 조합을 이룰 수 없는 상황이다.

일반적으로 핵연료주기 시뮬레이션 코드는 다음과 같은 기능을 갖고 있다.

- 물질 흐름 분석

다수의 동위원소와 동위원소 그룹을 추적하여 핵연료 주 기 옵션들의 분석을 위한 기초를 제공한다. 이러한 물질 흐 름 계산 결과로부터 물질 흐름상에 나타나는 발열량, 방사 능, 핵확산저항성 및 물리적 방호 등을 정량화 할 수 있다. 물질 흐름 분석은 시뮬레이션 코드에 연료 조성, 핵종변환, 분리, 폐기물 형태 자료와 같은 라이브러리를 필요로 한다.

- 비용 분석

핵연료주기 시뮬레이션 코드로 핵연료 주기 비용 분석의 기본이 되는 자본 비용, 운영 비용 등을 추적할 수 있다. 핵 연료주기 비용 분석은 핵연료주기 옵션들간의 비교를 통해 원자력 기술의 타 에너지원에 대한 경쟁성을 판단하는 데 사용될 수도 있다. 비용 분석은 전력 생산의 평준화 비용, 총 핵연료 주기 비용과 시설 전주기 비용 등을 포함한다.

- 경제성 분석

핵연료주기 시설 건설, 전력 생산, 물질들의 유용성 등과 같은 많은 파라메터들이 물질들과 공정들의 가격에 영향을 미치며 이들 정보들을 입력하여 동적 가격 시뮬레이션으로 핵연료주기의 경제성이 분석될 수 있다.

- 민감도 분석

핵연료주기 시뮬레이션 코드는 고려 대상인 핵연료주기 의 분석을 위해 입력 파라메터들의 영향성을 분석하여 핵연 료주기 최적화에 대한 결과를 도출할 수 있다.

- 불확실성 분석

핵연료주기 시뮬레이션 코드로 불확실성이 전파되는 것 을 분석하기 위해 불확실성이 분포된 핵연료주기 시뮬레이 션을 수행할 수 있으며 얻어진 결론으로부터 기초 데이터를 수정할 수 있는 유연성을 제공한다. 이것은 적절한 가정과 판단을 합리적으로 할 수 있는 정보를 제시한다.

최근에는 이와 같이 다양한 코드들의 장단점을 특정 시나 리오 하에서 비교하려는 움직임이 있었으며 Table 8[16]과 같이 상용으로 사용되는 5 개의 핵연료 주기 시뮬레이션 코 드들이 비교되었다.

$\mathrm{OECD/NEA}$ 에서는 시뮬레이션 코드들의 비교를 위해 (1) 직접처분 (Open cycle) (2) LWR로의 Pu 제한 순환 및 (3) 
Table 8. Characteristics of NFC simulation codes.

\begin{tabular}{|c|c|c|c|c|c|}
\hline & cosi6 & DESAE2. 2 & EVOLOCODE & FAMILY21 & VISION2.2 \\
\hline Language & Java & & Fortran & $\begin{array}{c}\text { MS Visual } \\
\text { Basic }\end{array}$ & \begin{tabular}{|c|} 
System \\
Dynamics/ \\
Power Sim
\end{tabular} \\
\hline User interface & Yes & Yes & Text interface & Yes & Yes \\
\hline $\begin{array}{l}\text { Simultaneous } \\
\text { advanced } \\
\text { technologies } \\
\text { scenarios }\end{array}$ & $\begin{array}{c}\text { Any combination } \\
\text { of LWR, HTR, } \\
\text { HWR, FR, ADS } \\
+\begin{array}{c}\text { different types } \\
\text { of fuels }\end{array}\end{array}$ & Yes & $\begin{array}{c}\text { Any reactor } \\
\text { with any fuel }\end{array}$ & $\begin{array}{c}\text { Any } \\
\text { combination } \\
\text { of LWR, HWR, } \\
\text { FR, ADS + } \\
\text { different } \\
\text { types of fuels }\end{array}$ & $\begin{array}{l}\text { One-tier, two- } \\
\text { tier scenarios } \\
\text { (+ choice of } \\
\text { the number } \\
\text { of recycling) }\end{array}$ \\
\hline $\begin{array}{l}\text { Isotopic } \\
\text { tracking }\end{array}$ & $\begin{array}{c}\text { Yes (Isotopes } \\
\text { of } \\
\mathrm{U} / \mathrm{Pu} / \mathrm{MA} / 200 \\
\mathrm{FP})\end{array}$ & $\mathrm{U}, \mathrm{Pu}, \mathrm{MA}$ & $\begin{array}{l}\text { Yes }(\sim 3300 \\
\text { isotopes })\end{array}$ & $\begin{array}{c}\text { Yes } \\
\text { (Isotopes of } \\
\text { U/Pu/MA/ } \\
880 \mathrm{FP} \text { ) }\end{array}$ & $\begin{array}{c}\text { Yes } \\
\text { (Follows } \\
\text { up to 81 } \\
\text { isotopes) }\end{array}$ \\
\hline $\begin{array}{c}\text { Calculation of } \\
\text { depletion in } \\
\text { cores }\end{array}$ & $\begin{array}{c}\text { Depletion } \\
\text { code CESAR } \\
\text { with one-group } \\
\text { cross sections } \\
\text { libraries. Direct } \\
\text { coupling with } \\
\text { ERANOS } \\
\text { possible }\end{array}$ & $\mid \begin{array}{c}\text { No coupling } \\
\text { with } \\
\text { transmutation } \\
\text { code }\end{array}$ & $\begin{array}{c}\text { Creation of one } \\
\text { group cross } \\
\text { sections with } \\
\text { EVOLOCODE2. } \\
\text { Possibility of } \\
\text { choosing } \\
\text { reference } \\
\text { libraries }\end{array}$ & $\begin{array}{c}\text { Stored } \\
\text { depletion } \\
\text { matrix based } \\
\text { on results of } \\
\text { depletion } \\
\text { calculation by } \\
\text { the ORIGEN2 } \\
\text { code }\end{array}$ & $\begin{array}{c}\text { Precalculated } \\
\text { fuel recipes } \\
\text { with } \\
\text { interpolation } \\
\text { (as a functioin } \\
\text { of the } \\
\text { number of } \\
\text { cycles) }\end{array}$ \\
\hline $\begin{array}{l}\text { Start up and } \\
\text { shut down } \\
\text { fuel loads }\end{array}$ & Yes & $\begin{array}{l}\text { Start up } \\
\text { only }\end{array}$ & Yes & Yes & No \\
\hline $\begin{array}{l}\text { Front-end fuel } \\
\text { cycle facilities }\end{array}$ & $\begin{array}{l}\text { All facilities } \\
\text { represented }\end{array}$ & Enrichment & Enrichment & $\begin{array}{l}\text { Enrich } \\
\text { fabric }\end{array}$ & $\begin{array}{l}\text { Enrich } \\
\text { fabric } \\
\end{array}$ \\
\hline $\begin{array}{c}\text { Reprocessing } \\
\text { plants }\end{array}$ & Represented & Represented & Represented & Represented & Represented \\
\hline $\begin{array}{c}\text { Spent fuel to } \\
\text { be } \\
\text { reprocessed }\end{array}$ & $\begin{array}{c}\text { User choice: } \\
\text { "first-in first- } \\
\text { out" or "last-in } \\
\text { first-out" }\end{array}$ & $\begin{array}{l}\text { "first-in first- } \\
\text { out" only }\end{array}$ & $\begin{array}{l}\text { User choice: } \\
\text { "first-in first- } \\
\text { out" or "last- } \\
\text { in first-out" }\end{array}$ & $\begin{array}{l}\text { User choice: } \\
\text { "first-in first- } \\
\text { out" or "last- } \\
\text { in first-out" }\end{array}$ & $\begin{array}{l}\text { User choice: } \\
\text { "first-in first- } \\
\text { out" or "last- } \\
\text { in first-out" }\end{array}$ \\
\hline $\begin{array}{c}\text { High level } \\
\text { waste package } \\
\text { calculation }\end{array}$ & $\begin{array}{c}\text { Yes + time } \\
\text { dependant } \\
\text { radiotoxicity } \\
\text { and decay heat }\end{array}$ & No & No & Yes & Yes \\
\hline $\begin{array}{c}\text { Repository } \\
\text { requirement } \\
\text { assessment }\end{array}$ & Yes & No & No & No & Yes \\
\hline
\end{tabular}

$\mathrm{Pu}$ 및 $\mathrm{MA}$ 의 고속로 순환의 세 가지 시나리오를 설정하였다 [16]. 120 년의 기간을 산정하여 시뮬레이션을 한 결과 전반 적으로 비교 대상 코드들은 3 개 시나리오 모두 유사한 경향 을 나타냈으며 시나리오 1 에 대해서는 서로 매우 근접한 결 과를 보여주었다. 시나리오 2와 3에서는 경향은 동일하였으 나 일부 차이를 나타내고 있었으며 이는 초기 가정 때문인 것으로 해석되었다. 따라서, 수렴된 결과를 얻기 위해서는 반복 계산이 필수적이며 가정들을 검토하여 조정할 필요가 있게 된다. 이는 코드들이 초기 조건을 해석하고 가정되지 않은 상황은 코드 특성에 맞춰 설정하는 것에서 차이가 발 생하기 때문이다.

\section{$\mathrm{V}$. 결 론}

핵연료주기 분석은 선진 핵연료주기 개발을 위해 연구 단 계의 기술들을 통합하고 대안 기술들을 도출 비교 분석 평 가하여 최적 핵연료주기 구현을 위해 보다 체계적으로 연 구 개발을 추진할 수 있도록 방향을 제시하는 역할을 수행
한다. 이와 같은 핵연료주기 분석의 역할과 방법을 이해하 기 위해 본 연구에서는 핵연료주기 분석 전략과 선진 핵연 료주기 개발을 위한 접근 방법들에 초점을 맞추었다.

본 연구에서 제시한 시스템 분석 방법들의 관계는 Fig. 8 과 같다. 핵연료주기 정책 결정을 위해 선진 핵연료주기는 전략적으로 기술적 분석을 하고 국내외 이해관계와 국가 에너지 정책과 연계되어야 한다. 다양한 핵연료주기들의 거동과 영향이 이해되어야 하며 이는 핵연료주기 시스템 분석을 예측을 위한 전략적 도구로 활용하여 얻을 수 있다. 방법적 측면에서 트레이드 연구가 핵주기 시스템 분석 연 구에 적합하게 활용될 수 있다. 트레이드 연구는 비교 대상 을 지표별로 분석하여 평가하는 방법으로 선진 핵연료주기 의 목표와 같이 친환경성, 지속가능성 등을 지표로 사용한 다면 핵연료주기 분석에 활용될 수 있다. 트레이드 연구는 비교를 위해 평가 지표를 설정하여 핵연료주기에 따라 평 가 지표를 정량 또는 정성적으로 평가하여 비교할 수 있는 방안을 제시한다. 이를 위해 각 평가 지표에 해당하는 정보 들을 기술성숙도(TRL) 분석법 및 핵주기 시뮬레이터 등과 같은 방법들을 사용하여 획득하고 지표에 대한 가중치를 부여하여 목표로하는 선진 핵 연료주기를 제시하게 된다.

기술적 발전 수준 평가는 기술 개발 수준과 프로그램 목 표와의 차이를 파악하여 연구 개발의 방향과 일정 관리를 위해 우선적으로 수행되어야하는 연구 활동으로 이를 위해 현재 기술 단계를 평가하기 위한 방법으로 TRL 분석 방법 이 활용되고 있다. 이 방법을 통해 분석된 결과는 기술성숙 도와 같은 평가 지표로 트레이드 연구를 위한 입력자료로 활용된다.

핵연료주기별 우라늄 소모량, 처분장 면적 및 비용 등은 각각이 중요한 평가 지표로서 핵연료주기 시뮬레이터를 활 용하여 얻을 수 있다. 시뮬레이터에서 제공하는 동적 모델 링으로 시간에 따른 우라늄의 소모량 등에 대해 핵연료주 기별로 비교 분석할 수 있으며 현재 다양한 핵연료주기 시
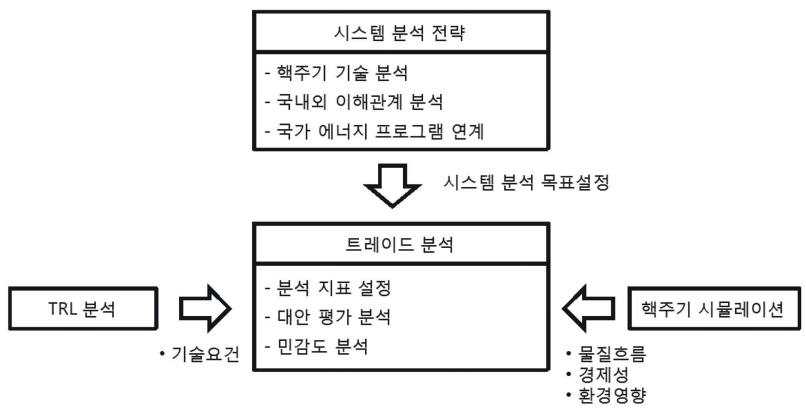

Fig. 8. Relationships of system analysis methods. 
뮬레이션 코드들이 개발되어 사용되고 있다. 그러나, 이러 한 코드를 사용할 때에는 가정과 초기 조건들을 면밀히 검 토하고 반복적인 계산으로 결과를 수렴시켜야 오차를 줄일 수 있게 된다. 시뮬레이션 코드를 사용하여 여러 핵연료주 기의 동적 물질흐름, 환경영향 등을 빠르고 정확하게 계산 할 수 있으며 동적 모사 결과는 트레이드 연구의 다양한 지 표에 활용되어 핵연료 주기 비교를 위한 중요한 정보를 제 공하게 된다.

핵연료주기 분석은 일단의 선진 핵연료주기를 도출하여 종료되는 연구는 아니며 끊임없이 개발되는 기술적 연구 결과를 조사하여 반영하고 변화하는 사회적 요구 사항들을 파악하여 지속적으로 핵연료주기에 적용하여 분석하는 과 정을 반복적으로 수행하는 연구이다. 이 연구 결과는 다시 연구 개발에 대한 방향 설정에 활용되어 연구와 분석이 선 순환되는 구조를 이루게 될 것이다. 따라서, 선진 핵연료주 기 도출을 위해 핵연료주기분석 연구 역시 핵연료주기를 구성하는 세부 기술들과 함께 지속적으로 개발되어야 하며 본 연구에서 제시한 방법적 틀을 바탕으로 다양한 기법들 이 개발되어야 할 것이다.

\section{감사의 글}

본 연구는 지식경제부 방폐물관리기술개발 중장기기획과 제(2009T100200033)의 일환으로 수행되었습니다.

\section{참고문헌}

[1] U.S. DOE Report, "Report to Congress on Advanced Fuel Cycle Initiative: The Future Path for Advanced Spent Fuel Treatment and Transmutation Research," January (2003).

[2] J. W. Herczeg, "Fuel Cycle Research and Development Overview," FY2011 NEUP Workshop, Rockville, U.S., 27-28 July (2010).

[3] B. Williams, "The Fuel Cycle R\&D Program Systems Analysis," FY2011 NEUP Workshop, Rockville, U.S., 27-28 July (2010).

[4] B. Savage, "Fuel Cycle Research and Development: Moving to a Long-Term, Science-Based, GoalOriented Program," Fuel Cycle Information Exchange, Bethesda, U.S., June 29-July 1 (2010).

[5] C. J. Jeong and W. I. Ko, "Scenario Analysis for a
Transuranic Transmutation by Using Fast Reactors Compared to Accelerator Driven Systems," Energy Conversion and Management, 49, pp. 1917-1921 (2008).

[6] B. H. Park, F. Gao, E.-H. Kwon, and W. I. Ko, "Comparative Study of Different Nuclear Fuel Cycle Options: Quantitative Analysis on Material Flow," Energy Policy, 39, pp. 6916-6924 (2011).

[7] NASA, "NASA Systems Engineering Handbook", NASA/SP-2007-6105 Rev1 (2007).

[8] S. J. Piet, G. E. Matthern, J. J. Jacobson, C. T. Laws, L. C. Cadwallader, A. M. Yacout, R. N. Hill, J. D. Smith, A. S. Goldmann, and G. Bailey, "Fuel Cycle Scenario Definition, Evaluation, and TradeOffs", INL Report, INL/EXT-06-11683 (2006).

[9] D. M. Tendall and C. R. Binder, "Nuclear Energy in Europe: Uranium Flow Modeling and Fuel Cycle Scenario Trade-Offs from a Sustainability Perspective", Environmental Science \& Technology, 45, pp. 2442-2449 (2011).

[10] W. L. Nolte, B. C. Kennedy, and R. J. Dziegiel Jr., "Technology Readiness Level Calculator," NDIA Systems Engineering Conference, San Diego, U.S. 20-23 October (2003).

[11] L. Holten, D. Alexander, C. Babel, H. Sutter, and J. Young, "Technology Readiness Assessment for the Waste Treatment and Immobilization Plant (WTP) Analytical Laboratory, Balance of Facilities and LAW Waste Vitrification Facilities," DOE Report, 07-DESIGN-042 (2007).

[12] K. O. Pasamehmetoglu, "Definition of Technology Readiness Levels for Transmutation Fuel Development", INL Report, GNEP-FUEL-TD-RT2008-000051 (2008).

[13] K. Minato, Y. Morita, K. Tsujimoto, S. Koyama, M. Kurata, T. Inoue, and K. Ikeda, "Technology Readiness Levels for Partitioning and Transmutation of Minor Actinides in Japan", OECD/NEA 11IEMPT, San Francisco, U.S., 1-4 November (2010).

[14] GNEP Technical Integration Office, "Global Nuclear Energy Partnership Technology Development Plan", 
GNEP Report, GNEP-TECH-TR-PP-2007-00020, Rev 0 (2007).

[15] J. J. Laidler, "GNEP Spent Fuel Processing; Waste Streams and Disposition Options", NWTRB, Washington D.C., U.S., 15 May (2007).

[16] L. Boucher, F. A. Velarde, E. Gonzalez, G. W. Dixon, G. Edwards, G. Dick, and K. Ono, "International Comparison for Transition Scenario Codes Involving COSI, DESAE, EVOLCODE, FAMILY and VISION", OECD/NEA 11IEMPT, San Francisco, U.S., 1-4 November (2010). 